\title{
The Nomological Argument for the Existence of God
}

\author{
Forthcoming in Noûs * \\ Tyler Hildebrand, Dalhousie University \\ Thomas Metcalf, Spring Hill College
}

\begin{abstract}
According to the Nomological Argument, observed regularities in nature are best explained by an appeal to a supernatural being. A successful explanation must avoid two perils. Some explanations provide too little structure, predicting a universe without regularities. Others provide too much structure, thereby precluding an explanation of certain types of lawlike regularities featured in modern scientific theories. We argue that an explanation based in the creative, intentional action of a supernatural being avoids these two perils whereas leading competitors do not. Although our argument falls short of a full defense, it does suggest that the Nomological Argument is worthy of philosophical attention.
\end{abstract}

\section{Sketch of the Nomological Argument}

According to the Nomological Argument, a supernatural being provides the best explanation of regularities in nature, such as that planets have elliptical orbits, that the speed of light is the same in all frames of reference, and that quantum systems evolve in accordance with the Schrödinger equation. Although we can't provide a full defense in this paper, we will identify the leading competing hypotheses and argue that Divine Voluntarism — the hypothesis that regularities are explained by a supernatural beingbeats them when it comes to two most-crucial explanatory virtues. This at least makes a strong prima facie case for preferring Divine Voluntarism to its leading competitors and clarifies how the Nomological Argument is to be defended. ${ }^{1}$

\footnotetext{
* This is the penultimate draft. The official version: http://doi.org/10.1111/nous.12364

1 Divine Voluntarism has received some recent attention (Foster 2004, Swinburne 2006, Collins 2009a, Orr 2019). However, these discussions have been limited in various respects-
} 
We'll begin with a toy example to illustrate the argument's basic structure and to clarify what we mean by 'explanation'.

Poker: Suppose that you're playing poker with Al, who deals himself a sequence of five consecutive royal flushes $(S)$. Naturally, you consider the following two hypotheses:

Fair (F): The cards were dealt from fairly shuffled decks.

Cheating (C): Al manipulated the decks.

Presumably you're justified in preferring $C$ to $F$. $C$ has the best balance of two dialectical virtues. First, it's at least somewhat plausible independently of the observed sequence $S$. Second, $C$ makes $S$ plausible, whereas $F$ doesn't at all.

We can use the odds form of Bayes' theorem to make this reasoning more precise.

$$
\text { Bayes' Theorem: } \frac{P\left(H_{1} \mid O\right)}{P\left(H_{2} \mid O\right)}=\frac{P\left(O \mid H_{1}\right) P\left(H_{1}\right)}{P\left(O \mid H_{2}\right) P\left(H_{2}\right)}
$$

On the left, we have the posterior ratio, $\frac{P\left(H_{1} \mid O\right)}{P\left(H_{2} \mid O\right)}$. Its terms are conditional probabilities. They describe how probable each hypothesis $H$ is given an observation $O$. The first ratio on the right is the likelihood ratio, $\frac{P\left(O \mid H_{1}\right)}{P\left(O \mid H_{2}\right)}$. Its terms are conditional probabilities as well, but they describe how probable the observation $O$ is given each hypothesis $H$. The second ratio on the right is the prior ratio, $\frac{P\left(H_{1}\right)}{P\left(H_{2}\right)}$. Its terms describe how probable each hypothesis is prior to the observation. Hence, they're called prior probabilities. Our

for example, none carefully considers the now-popular Primitivism about laws (see Section 2). As a result, it is difficult to extract a plausible Nomological Argument from extant discussion. The Nomological Argument bears some similarities to the older Eutaxiological Argument (cf. Barrow and Tipler 1986: 29), which we'll discuss later in this section. 
argument is probabilistic, rather than an explicit inference to the best explanation. ${ }^{2}$ However, we'll assume that the hypothesis that best explains an observation is the one with the highest posterior probability. Thus, Bayes' theorem implies that the best hypothesis has the best balance of likelihood and prior probability. (Note that the posterior ratio is greater than 1 whenever the likelihood ratio is greater than the inverse prior ratio, $\frac{P\left(H_{2}\right)}{P\left(H_{1}\right)}$.

Let's apply this to Poker. We'll suppose that $P(F)$ is greater than $P(C)$, because fair play is more common than competent cheating. As far as priors are concerned, the scales tip toward $F$. However, it seems that $P(S \mid C)$ is much greater than $P(S \mid F)$, because $P(S \mid F)$ is extremely low. ${ }^{3}$ As far as likelihood is concerned, the scales tip toward $C$. Intuitively, the difference in likelihood swamps the difference in priorsmore precisely, the likelihood ratio $\frac{P(S \mid C)}{P(S \mid F)}$ is greater than the inverse prior ratio $\frac{P(F)}{P(C)}$ so $C$ is the better explanation. For reasons we'll discuss later (in $\ 5$ ), there are important background assumptions relevant to the assignments of priors. But we can ignore this complication for now.

At this point, you may be wondering how these probabilities are to be interpreted. ${ }^{4}$ They don't merely report frequencies, either actual or hypothetical. And they don't describe objective chances, because either $\mathrm{Al}$ cheated or he didn't. Rather, they have an epistemological character. Perhaps they are subjective epistemic probabilities (credences) that describe your subjective degrees of belief in the relevant propositions. Or perhaps (as we prefer to think of them) they are objective epistemic probabilities that describe how strongly you ought to believe the propositions given your total evidencei.e., that describe what your credences ought to be. We'll say more about interpretations of probability in Section 5, but we can remain neutral between these two epistemological interpretations for now. If you think of the probabilities as objective epistemic probabilities, the argument above shows that we ought (in an epistemic sense) to believe that $\mathrm{Al}$ is cheating in light of our total evidence. In contrast,

2 Of course, one might argue that inference to the best explanation, if coherent, is ultimately just Bayesian inference (Climenhaga 2017).

3 The probability of getting a royal flush on any given fairly dealt hand in a game of Texas Hold 'Em, a popular version of poker, is approximately 1 in 31,000.

${ }^{4}$ For introductions to interpretations of probability, see Mellor (2005) and Hájek (2019). 
if you think of them as subjective epistemic probabilities, and you don't think there are any constraints on the assignment of priors, the argument above merely shows that it is rational for those who agree with our assignments of probabilities to be confident that $\mathrm{Al}$ is cheating. ${ }^{5}$ Similar remarks apply to the interpretation of probabilities involved in the Nomological Argument.

The Nomological Argument is based on the idea that someone imposes order on nature in much the same way that a cheater imposes order on a deck of cards. In the rest of this section we'll sketch the argument, motivate it on an intuitive level, and identify some central challenges.

To begin, we'll say something about the notion of order involved in our version of the argument. Up to this point we have used terms such as 'regularity' and 'order' in their loose and popular senses; from now on we'll be precise. The general notion of a regularity or pattern is familiar, but our version of the Nomological Argument is based on a slightly more specific and more sophisticated notion of a pattern — roughly, the sort of pattern that is described by statements of laws in modern scientific theories, all of which have a mathematical character. Consider Newton's Law of Universal Gravitation: $F_{G}=G \frac{m_{1} m_{2}}{d^{2}}$. The terms in scientific equations such as this describe precise quantities of physical properties — in this case, determinate quantities of determinable properties of Force, Mass, etc. Any other example of a dynamical law would work just as well as an illustration, because the precise content of laws and the regularities they describe is not what matters. The Nomological Argument is not based on the fact that our universe contains the exact regularities that it does in fact contain. ${ }^{6}$ Rather, it is based on the more general claim that the observed parts of nature contain regularities involving a certain level of sophistication, such that they can be adequately described only with the language of mathematics. (Categorical logic, for example, is not up to the task.) Henceforth, whenever we use the term regularity (R) and its cognates we have in mind the sorts of regularities distinctive of laws of modern scientific

${ }^{5}$ If the italicized clause makes the argument sound underwhelming, it's worth pointing out that subjectivists think such a clause applies to all probabilistic arguments.

${ }^{6}$ That would lead us in the direction of a fine-tuning argument, making it vulnerable to the objection that it's extremely improbable that God would select exactly this set of regularities as opposed to another; cf. White (2000: 272) and Metcalf (2018: 17-18). 
theories. When we need to talk about patterns in a more general sense, we'll use the terms patterns or order. Thus, all regularities are patterns, but not all patterns are regularities; all worlds with regularities are orderly, but not all orderly worlds contain regularities. When we need to discuss a pattern that is not a regularity, we'll call it a mere pattern. Likewise, an orderly world with no regularities has mere order.

The Nomological Argument is distinguished from other a posteriori arguments for the existence of God primarily by its use of evidentiary statement $R$ as opposed to some other evidentiary statement. Cosmological arguments are based on even more general or abstract features of the world, such as the mere presence of contingency. Fine-tuning arguments (and other design arguments) are based on highly specific features of the universe, such as the fact that nature contains laws whose content involves constants that fall within an extremely narrow range of values capable of supporting life. Thus, the Nomological Argument is in an intermediate position between cosmological arguments and standard design arguments. This confers some advantages. For example, like contingency, regularity is a fairly abstract, general feature of the world. But it's more obvious than contingency, since it does not require us to detect the modal qualities of the world. It merely requires us to be in the position to notice that nature's patterns can be described in precise, quantitative terms. Moreover, the mere fact that nature contains regularities is much more obvious than the fact that it contains the specific design-like regularities featured in standard design arguments. Arguably, modern science would not be possible if there were no regularities, so we can think of the Nomological Argument as an argument for the existence of a supernatural being based on the mere possibility of doing modern science. As a result, the Nomological Argument is much less sensitive than standard design arguments to changes in our best science. As for other design arguments, the Nomological Argument is a close relative of, or perhaps a version of, the Eutaxiological Argument, which is based on the general orderliness and comprehensibility of the universe (cf. Barrow and Tipler 1986: $29 \mathrm{ff}$ and Manson 2003: 2). ${ }^{7}$ However, as noted above, the claim that our world contains regularities is more specific than the claim that it is orderly, and the Nomological Argument isn't concerned with comprehensibility per

\footnotetext{
${ }^{7}$ We thank an anonymous referee for suggesting that we draw attention to this connection.
} 
se. Since the Nomological Argument is based on the explanation of lawlike regularities distinctive of modern science, rather than an explanation of mere order and comprehensibility, we think it is appropriate to introduce a new title: hence the label 'Nomological.'

As noted above, the Nomological Argument shares the same basic form as our reasoning about the Poker case. The question, then, is what sorts of hypotheses might be introduced to explain regularities. Here are two (don't worry; we'll consider more later):

Humeanism (H): The distribution of properties in our world is simply a brute fact: a basic feature of our metaphysics for which there is no metaphysical explanation. ${ }^{8}$

Divine Voluntarism $(G)$ : There is an intelligent being that has the power to intentionally control the distribution of properties in our worldthat is, whether there are regularities or mere patterns or no patterns at all. ${ }^{9}$

We'll call the intelligent being featured in Divine Voluntarism God. However, Divine Voluntarism does not claim that God is omnipotent, omniscient, and morally perfect. It doesn't even claim that God is a person who cares about us. ${ }^{10}$ In any case, just as we argued that Cheating is better than Fair in light of observed sequence $S$, you can argue that Divine Voluntarism is better than Humeanism in light of observed regularities R. For

8 Humeanism is so-called because it does not countenance any necessary connections. Proponents include those who reduce laws to regularities in a Humean base (Lewis 1973, Loewer 1996, Beebee 2000, Schaffer 2008), and also those who deny necessary connections while rejecting reductive Humean analyses of laws (van Fraassen 1989).

9 Recent proponents include Foster (2004), Swinburne (2006), and Collins (2009a). Divine Voluntarism was popular during the Early Modern period, with Descartes, Malebranche, Berkeley, and perhaps Newton as proponents (Ott 2009, especially 1.1 and Chapter 7).

${ }^{10}$ Divine Voluntarism doesn't say how God brings about regularities. For example, it can be paired with occasionalism (Plantinga 2016), dispositionalism (Adams 2018), and natural kind essentialism (Dumsday 2012, 146). This is an issue internal to the theory, and we won't discuss it further. 
example, you might concede that $P(G)<P(H)$, but argue that $P(R \mid G)>>P(R \mid H)$. By Bayes' Theorem, these premises imply that $P(G \mid R)>P(H \mid R) .{ }^{11}$

Let's now consider the specific probabilities involved in the Nomological Argument, beginning with the priors. Prior to observing regularities, Humeanism may seem more plausible than Divine Voluntarism. After all, positing a god may seem ontologically profligate, and Divine Voluntarism may seem to be a more-specific metaphysical hypothesis than Humeanism, and therefore a hypothesis that's somewhat less modest. Thus, let's suppose that $P(H)>P(G)$. But is it really that much greater? $G$ and $H$ are both metaphysical hypotheses; both are fairly general (remember, we've said very little about God!); arguably considerations of parsimony don't count for all that much; there are very smart experts on both sides; and metaphysics is really hard. For these reasons, it would be surprising if we could justify vastly different priors for $P(H)$ and $P(G)$ — say, a difference of more than a few orders of magnitude.

Let's turn to $P(R \mid H)$. Humeanism stipulates that the actuality of our world, as opposed to any other Humean world, is simply a brute fact. In denying that there are necessary connections between distinct existences, Humeanism commits itself to a recombination principle concerning particular matters of fact: any distribution of properties is possible. The result is an extremely large class of epistemically possible Humean worlds, the vast majority of which do not contain widespread and systematic regularities. Nothing in the Humean ontology suggests that we should assign a higher prior probability to some worlds (namely, the ones with regular property distributions) than others (namely, the irregular ones). Thus, $P(R \mid H)$ is extremely low, because regularities occur in only a miniscule proportion of Humean possible worlds. ${ }^{12}$

${ }^{11}$ Of course, the Total Evidence Requirement demands that we take into account all the relevant evidence, and perhaps there is some evidence that could also pro tanto lower $\mathrm{P}(\mathrm{G})$ or raise $\mathrm{P}(\mathrm{H})$. We can't consider all such arguments, but we'll discuss a couple of possibilities below, in $\iint 4$ and 5 .

12 For defenses of this controversial claim, see Armstrong (1983), Fales (1990, especially Chapter 4), Bird (2007, 86-90), Tooley (2011), Hildebrand (2013), Filomeno (2019), and Segal (forthcoming). Though it's controversial, we won't say more in defense of it, except to briefly discuss one potential objection relevant to statement $R$. You might worry that we've ignored an observation selection effect. Suppose for the moment that we live in an infinitely large Humean universe. Then we should not expect to observe irregularity, since if we were in an irregular part of the universe life wouldn't be possible. Nevertheless, certain features of our actual observation of regularity remain remarkable. If Humeanism were true, and if we were fully aware of the phenomena of observation selection effects, we would expect to live in a 
In contrast, we can think of reasons why a powerful, intelligent being would prefer to create regular worlds. Certain moral or aesthetic properties can be realized only in regular worlds, and an agent might have some preference for worlds that realize such properties. To elaborate very slightly, certain properties might require regularities - namely, patterns of the sort involved in modern scientific theories-over and above the relatively simpler sorts of patterns that can be stated using categorical logic alone. This is not to say that $P(R \mid G)$ is high; it's just to say that it's not terribly low. But given that $P(\mathrm{R} \mid H)$ is extremely low, $P(\mathrm{R} \mid G)>>P(\mathrm{R} \mid H)$.

Summing up, the Nomological Argument seems to be analogous to our reasoning about the Poker case in at least the following respects. ${ }^{13}$ Cheating $C$ is better than Fair $F$, because although it has a lower prior $(P(C)<P(F))$, it has a vastly higher likelihood $(P(S \mid C)>>P(S \mid F))$. Divine Voluntarism $G$ is better than Humeanism $H$, because although it may have a lower prior $(P(G)<P(H))$, it has a vastly higher likelihood $(P(R \mid G)>>P(R \mid H))$. This ends our preliminary sketch of the argument. Let's turn to some initial objections.

First, it is controversial, especially to empiricists and skeptics about metaphysics per se, whether metaphysical explanations of this sort are possible in the first place. For example, you might be sympathetic to van Fraassen's (1989, Chapter 6) critique of inference to the best explanation. Relatedly, you might harbor doubts about our ability to assign probabilities to metaphysical hypotheses. ${ }^{14}$ For example, we rely on a version of the Principle of Indifference at various points in our argumentsfor example, to assign likelihoods such as $P(R \mid H)$-but the Principle is susceptible to

universe in which regularity is widespread, but only locally, since it is only local regularity that is required to support life. But we don't observe this; instead, we observe regularity as far as observation takes us. To this point, a referee suggested the example of laws of physics' breaking down at high energy levels. We reply that normally, scientists conclude not that nature is irregular but that our old theories failed to accurately describe the fundamental regularities. 13 There are, of course, respects in which the two cases aren't analogous. For example, our shared background knowledge that makes the assignment of probabilities uncontroversial in the Poker case. However, we're not giving an argument from analogy. The Poker case is just a heuristic.

${ }^{14}$ Here are two. First is the problem of the priors, which concerns the difficulty of assigning nonarbitrary prior probabilities to hypotheses of the sort we're considering. (See Weisberg 2019 for an accessible introduction.) This is essentially the old empiricist objection that rational intuition is mysterious, applied to probabilistic contexts. Second is a concern about assigning probabilities to sample spaces that aren't normalizable (Manson 2009, McGrew et al. 2001, Collins 2005, Pruss 2005, McGrew and McGrew 2005). 
well-known objections. ${ }^{15}$ Despite this controversy, we'll simply assume that it's possible to defend explanatory arguments along these sorts of lines. Although the controversy is interesting and important, we don't have the space to engage with these objections in this paper. If you're worried about such objections, you may interpret our conclusion as a conditional: if we're capable of defending the explanatory superiority of any non-Humean theory of laws over Humeanism then we should accept Divine Voluntarism. That's an interesting conclusion regardless of your metaphysical or theological views. (We know a number of Humeans who would love to be able to say that non-Humeans are committed to belief in a supernatural being!)

Second, you can always object to an explanatory argument by proposing a competing explanation. In our first case, Poker, there is no plausible competing explanation of Al's sequence of hands. This is not so for regularities in nature. The literature on the metaphysics of laws is full of competing non-Humean theories that purport to explain regularities without appealing to a god. ${ }^{16}$ We need to consider these competing explanations to properly assess the Nomological Argument. We do so in Sections 2 and 3. As it turns out, explaining regularities with a non-Humean theory is harder than it looks. We'll argue that the leading non-Humean competitors to Divine Voluntarism have various explanatory shortcomings. Understanding the distinctive ways in which these theories fall short will help us to identify desiderata for a metaphysical explanation of regularities. In Section 4, we'll argue that Divine Voluntarism satisfies these desiderata." And in Section 5, we'll argue that Divine Voluntarism has a sufficiently high prior probability that it constitutes the all-thingsconsidered best available explanation of regularities among leading non-Humean theories. In other words, we'll argue that Divine Voluntarism beats its most popular competitors with respect to the two key explanatory virtues we've identified (though we'll stop short of arguing that it's more probable than not-i.e., that $P(G \mid R)>$ $P(\sim G \mid R))$. Thus, although we haven't provided a complete defense of the

\footnotetext{
${ }^{15}$ That said, we do think that our use of indifference-type reasoning is plausible in each specific application that features in the Nomological Argument. We are not committed to accepting a fully general version of the Principle, so we think we can sidestep some of the traditional criticisms (e.g. Fumerton (1995: 214-15)). For a recent defense of applications of the Principle to this sort of context, see Filomeno (2019).

16 See, for example, Armstrong (1983), Fales (1990, especially Chapter 4), Bird (2007: 86-90), Tooley (2011), and Hildebrand (2013).
} 
Nomological Argument, we hope to have said enough to show that it warrants attention.

\section{Primitivism and the Peril of Insufficient Structure}

\subsection{Setup}

In this section, we consider the simplest competing explanation to Divine Voluntarism: namely, that laws themselves are primitive (Carroll 1994; Maudlin 2007). This competing theory has been mostly ignored in extant discussions of Divine Voluntarism, but it has some noteworthy advantages. In simplified general form, the theory can be stated as follows:

Primitivism (L): Laws are primitive entities in our ontology. The locution 'it is a law that' functions as a modal operator governed by the following axiom: necessarily, for all statements $p$, 'it is a law that $p^{7}$ entails $p$

Primitivism and Divine Voluntarism are versions of non-Humeanism, since both invoke a primitive sort of necessity that imposes structure on the natural world. Both theories posit modal primitives with the goal of explaining regularities. Thus, it might seem that $P(R \mid L)$ is just as high as $P(R \mid G)$, so that the two theories are on a par with respect to likelihood. Moreover, since both theories explain by positing unobserved non-Humean entities_-primitive laws and a divine being, respectively-it may seem that the priors should be similar as well. If this is right, Divine Voluntarism is not better than Primitivism. If we want to defend the Nomological Argument, we had better find something wrong with Primitivism. ${ }^{17}$

\footnotetext{
17 There are various well-known objections to Primitivism-for example, that its primitives are illicit, that it falls prey to van Fraassen's (1989) inference problem, etc. However, analogous objections can be raised against Divine Voluntarism, and we think successful replies to those objections can be adapted by proponents of Primitivism.
} 


\subsection{Against Primitivism}

The objection we present is due to Hildebrand (2013), and it's based on the idea that Primitivism simply pushes the explanatory problem back a level. We'll explore this objection carefully for two reasons. First, Primitivism hasn't been carefully considered in extant defenses of the Nomological Argument. Second, the objection we raise might seem to apply equally well to Divine Voluntarism, so it's important to get clear on its details.

We'll introduce the objection by way of a second case.

Simulated Poker: You and Al are playing poker on Al's 1980s-era computer. As before, $\mathrm{Al}$ receives five consecutive royal flushes. Bothered by Al's remarkable sequence of hands, you consider the following two hypotheses:

Indeterministic Algorithm (LA): Shuffling is simulated by a genuinely indeterministic algorithm.

Cheating 2 (C): Al manipulated the algorithm.

You conclude that $\mathrm{Al}$ is cheating, but he argues that the following hypothesis is even better than Cheating 2:

Deterministic Algorithm (DA): Shuffling is simulated by a deterministic algorithm.

According to $D A$, the sequence of royal flushes was determined in advance by the algorithm. The probability of Al's sequence, given our deterministic algorithm, is 1 . That's even higher than the probability of the sequence given the Cheating 2 hypothesis! Moreover, $D A$ has a higher prior than Cheating 2. (Someone with Al's character is not likely to cheat, and genuinely indeterministic random number 
generators were rare in 1980s-era computing.) Therefore, you should be willing to play at least one more hand-or so $\mathrm{Al}$ argues.

We don't expect that you'll find Al's argument convincing. It would be surprising if $\mathrm{Al}$ received this sequence of hands given $L A$. But it would be just as surprising if $\mathrm{Al}$ received this sequence of hands given $D A$. To see why, consider these two interpretations:

$D A 1$ : Shuffling occurs by some deterministic algorithm.

$D A 2$ : Shuffling occurs by a deterministic algorithm that entails $S$.

The vast majority of deterministic algorithms don't produce sequence $S$. For this reason, the likelihood $P(S \mid D A 1)$ is extremely low. For exactly the same reason, the prior $P(D A 2)$ is extremely low. Thus, neither $D A 1$ nor $D A 2$ provides a good explanation of sequence $S$. $D A 1$ has a reasonably high prior, but an unacceptably low likelihood; $D A 2$ has a high likelihood, but an unacceptably low prior. ${ }^{18}$

There are some general lessons to be drawn from this case. First, entailment does not imply explanation. $D A 2$ entails, but does not explain, $S$. Second, the distinction between indeterminism and determinism is meaningless as far as epistemic probabilities are concerned. What matter are the spaces of possibilities. The spaces of possibilities for $I A$ and $D A$ are perfectly isomorphic (at least if the algorithms are supposed to approximate fair shuffling). Moreover, there's nothing about one hypothesis that makes certain epistemic possibilities more likely than others. It is because of this isomorphism that the two theories $I A$ and $D A$ are on an explanatory par.

Having considered this case, Hildebrand's (2013) objection to Primitivism is easy to state. The problem is that Primitivism and Humeanism are perfectly isomorphic. Since Humeanism doesn't offer a satisfying explanation of regularities, neither does Primitivism. Here's a recap of why the Humean explanation of regularities

\footnotetext{
18 This is a common dilemma for explanatory hypotheses. See, for example, Huemer (2016) on external world skepticism and Collins's $(2009 \mathrm{~b}, \mathbb{S} 7.2)$ response to the "more fundamental law" objection to FTA.
} 
is unsatisfying. Suppose we begin with a metaphysically privileged (i.e., the correct) language for describing Humean worlds. It includes terms required to describe spacetime-including at least terms for spatiotemporal relations or conventions for naming spacetime points-and predicates corresponding to natural properties. That's all. Since Humeanism rejects primitive necessity, it implies a recombination principle according to which any logically consistent description of a world in the Humean language describes a possible world. Thus, the language generates a space of epistemically possible worlds. Nothing in the Humean ontology makes any one world intrinsically more likely than another, so we ought to assign them equal probabilities. Because the vast majority of worlds don't exhibit regularities, $P(R \mid H)$ is very low.

If we endorse Primitivism, we'll introduce into our language the modal operator 'it is a law that', governed by the following axiom: necessarily, for all statements $p$, it is a law that $p^{\prime}$ entails $p$. Notice that this axiom provides no guidanceno restrictions whatsoever-concerning the type of statement to which the operator may be attached. Because the operator is primitive, there's no reason to expect the sentences to which it is attached to describe regularities. They could describe particular matters of fact, irregularities, gerrymandered facts, or whatever. After all, the operator simply attaches to arbitrary sentences in the (otherwise) Humean language. Thus, the spaces of epistemic possibilities for Humeanism and Primitivism are isomorphic. Moreover, nothing in either ontology provides any epistemic reason to think that some of the possibilities in a given space are a priori more likely to obtain than any other members of that space. (Suppose you're given only the following information about a possible world: it contains a primitive law. From your epistemic perspective, it is a priori much more likely that the "law" in question would make the universe less regular rather than more. $)^{19}$ Thus, we may conclude that $P(R \mid L)$ is low for the same reasons that $P(R \mid H)$ is low. The move from Humeanism to Primitivism is unhelpful in the same way that the move from $L A$ to $D A$ is unhelpful.

Perhaps there's an easy fix: just stipulate that primitive laws are the sorts of things that give rise to regularities.

19 Compare Tooley (2008) on logical-probability calculations that take into account the contributions of unknown factors. 
Primitivism Restricted (LR): Laws are primitive entities in our ontology. The locution 'it is a law that' functions as a modal operator governed by the following axiom, subject to the restriction below: necessarily, for all statements $p$, "it is a law that $p$ ' entails $p$. Restriction: The operator can only attach to statements that describe regularities.

In fact, both Carroll (1994, 21-27) and Maudlin (2007, 10-15) endorse restrictions of this sort. But the problem with $L R$ is that it maintains that restricted primitive laws are ontological primitives. For this reason, the move from Primitivism in its general form to Primitivism Restricted is analogous to the move from Deterministic Algorithm in its general form $D A 1$ to Deterministic Algorithm in its restricted form $D A 2$. The restriction is metaphysically arbitrary. As Hildebrand points out (2013: 7ff), there's no difference in ontology between a primitive law in the general sense and a primitive restricted law. The two theories accept the same spaces of epistemic possibilities, and are distinguished by a mere semantic difference: a primitive necessitating entity that gives rise to an irregularity deserves the label 'law' on the general theory but not on the restricted theory. By way of comparison, consider the following, narrow version of Humeanism:

Humean Regularity Theory (HRT): Humeanism is true and there are lawlike natural regularities.

Notice that $P(R \mid H R T)$ is much greater than $P(R \mid H)$. In fact, $P(R \mid H R T)=1$. But this theory acquires the virtue of a high likelihood only by trading away its prior, so that $P(R \mid H) P(H)=P(R \mid H R T) P(H R T)$. The tradeoff is necessary because the distinction between $H$ and $H R T$ is metaphysically arbitrary. One is just a more-restricted version of the other. It is the same for Primitivism and Primitivism Restricted: $P(R \mid L) P(L)=$ $P(R \mid L R) P(L R)$. The more-specific theory acquires a higher likelihood only by reducing its prior, so it does not offer a better explanation of regularities. 


\subsection{The Peril of Insufficient Structure}

When $\mathrm{Al}$ appeals to Deterministic Algorithm (in any of its forms) to explain $S$, he simply replaces the question 'Why did $S$ obtain?' with a question just as difficult: 'Why did we end up with this algorithm?' Similarly, when we appeal to Primitivism (in any of its forms) to explain regularities, we simply replace the question 'Why did the regularities obtain?' with a question just as difficult: 'Why did we end up with these laws: namely, laws that produce regularities?' This occurs because the spaces of epistemic possibilities for the facts we wish to explain $(S, R)$ are isomorphic to the spaces of epistemic possibilities compatible with each theory $(D A, L)$. This is the Peril of Insufficient Structure: the theory doesn't contain enough structure to explain the regularities we observe, or even the fact that nature is orderly. We've focused on Primitivism's inability to explain regularities, but our arguments in this section do not rely on the patterns being regularities. Humeanism has just as much difficulty explaining a toy pattern like "all Fs are Gs" as it does explaining a sophisticated regularity, and similarly for Primitivism. In Section 4 we'll argue that Divine Voluntarism avoids this peril. But first we'll consider more competing theories and describe a different explanatory peril.

\section{Other non-Humean theories}

In this section we'll consider some non-Humean theories that endow laws with internal metaphysical structure, and so seem to avoid the Peril of Insufficient Structure. Indeed, we'll argue in 3.1 that the probability of order given such theories is high-or much higher than on Humeanism. But in 3.2 we'll argue that these non-Humean theories face a different sort of problem: they struggle to explain regularities. In other words, although such theories have explanatory power over toy patterns such as "all Fs are Gs" they do not have explanatory power over the sophisticated sorts of regularities featured in modern science.

Disclaimer: We can't consider all competing non-Humean theories, and we can't give any single theory the attention it deserves. We aim for just enough detail to identify a different sort of peril. (However, we provide a general taxonomy of non-Humean theories in Section 5 and gesture at some widespread difficulties.) 


\subsection{Solution to the Peril of Insufficient Structure}

Hildebrand (2013) proposes a solution to the Peril of Insufficient Structure compatible with three main views in the metaphysics of laws: the Dretske-Tooley-Armstrong theory (henceforth DTA) according to which laws are relations between universals (Dretske 1977; Tooley 1977; Armstrong 1983); dispositionalist theories according to which fundamental properties are modally-laden dispositions (Mumford 2004; Bird 2007; Tugby 2013); and various forms of natural kind essentialism (Lowe 1989, 2006; Ellis 2001; Oderberg 2007; Dumsday 2013). These theories involve different modal primitives. ${ }^{20}$ DTA posits primitive modally-laden external relations between universals; dispositionalism builds primitive modality into the essences of properties; and natural kind essentialism posits a kind of modality that unifies multiple properties together such that a collection of properties forms a natural kind whose essence is characterized by the relevant properties. Since properties feature in all of these accounts, we'll call them property-based theories of laws.

These theories avoid the Peril of Insufficient Structure by positing modal relations among natural properties. The natural/non-natural distinction can be illustrated by way of example. Following Lewis (1983), we'll say that properties are classes. Consider the class of green things. All and only green objects seem to be genuinely similar to one another in at least one respect-namely, in their color. Now consider the class of grue things, where an object is grue iff it is green and examined before time $t$ or blue and unexamined before $t$ (Goodman 1955, 74). Intuitively, there's no guarantee that any two grue objects will be genuinely similar in color. To use an even more extreme example, contrast the classes $\{x: x$ is an electron $\}$ and the Mona Lisa, the northern hemisphere of Pluto, the empty set $\}$. The members of the first class seem to be exactly similar; the members of the second seem entirely dissimilar. In sum, some properties (classes) seem to capture genuine similarity; others do not. The former are more natural than the latter. ${ }^{21}$

\footnotetext{
${ }^{20}$ We're using 'modal' in a broad sense, so that primitives like natural kind essence (that are strictly non-modal but have modal implications concerning property distributions) count as modal primitives.

${ }^{21}$ For more on the natural/non-natural distinction, see Lewis (1983), Armstrong (1989), and Sider (2011).
} 
As we saw above, there is no reason to expect an arbitrarily selected primitive law to produce a regularity, or even a mere pattern. However, there is reason to expect an arbitrarily selected property-based law to give rise to some sort of order. Propertybased theories incorporate primitive modal connections into networks of natural properties. For DTA, they are external relations that bind first-order universals (where universals are understood to be the ground of natural properties); for dispositionalism, relations of manifestation and, if applicable, stimulus conditions form a network of natural properties; and similarly for natural kind essentialism. If there is a DTA law $N(F, G)$, where $N$ is the relation of nomic necessitation, the pattern that "all Fs are Gs" must follow. As instances of dispositions enter appropriate stimulus conditions, they must manifest. And if a natural kind $K$ is characterized by natural properties $F$ and $G$, anything that becomes $K$ must also acquire $F$ and $G$. If any necessary connection holds among natural properties, it seems inevitable that a pattern will result, at least in the long run. Conversely, consider a sentence $D$ describing the particular matters of fact at a wholly disorderly world. Primitivism allows $D$ to be a statement of law, but property-based theories seem not to allow this, since there is no clear way to translate $D$ into a statement about nomic relations between universals, fundamental dispositions, or natural kinds. ${ }^{22}$ As a result, property-based theories appear to be better equipped to explain order than Primitivism. The prior probability that some propertybased theory is true (we'll use the label $N$, short for 'non-Humean property-based theories'), let us suppose, is similar to that of Primitivism: $P(N)=P(L)$. But if the preceding discussion is correct, it would appear that the likelihoods concerning order (O) are very different: $P(O \mid N)>>P(O \mid L)$. Thus, when it comes to the Peril of Insufficient Structure, we'll grant that property-based theories appear to have an advantage over Primitivism.

22 Possible exception: If we allow fundamental nomic relations of arbitrary complexity, the space of possible nomic relations might turn out to be isomorphic to the space of possible primitive laws, leading us back to the Peril of Insufficient Structure. This insight underlies Beebee's (2011) objection to non-Humean solutions to the problem of induction, but see Hildebrand (2018) for a response. 


\subsection{Against property-based theories}

Property-based theories avoid the Peril of Insufficient Structure by incorporating additional metaphysical structure into their accounts of laws and properties. As we saw, this places restrictions on lawhood; not just any sentence can be a statement of law. But this additional structure comes with a cost.

It's one thing to provide a metaphysical theory that explains toy patterns such as "all Fs are Gs." It's another thing entirely to provide a metaphysical theory that explains the sophisticated regularities of modern science. Indeed, the literature is full of putative examples of sophisticated regularities that property-based theories are illequipped to explain. For example, it has been argued: that dispositionalists and natural kind essentialists struggle to explain conservation laws $;^{23}$ that dispositionalists struggle to explain retention laws (namely, the regularity that things are disposed to retain their dispositions over time in the absence of interferences); ${ }^{24}$ and that all property-based accounts struggle to explain functional laws, ${ }^{25}$ idealized laws ${ }^{26}$ and putatively lawlike boundary conditions such as the Past Hypothesis (according to which the universe began in a low entropy state). ${ }^{27}$ These problems arise because it is difficult to translate statements of sophisticated laws-i.e., laws that describe regularities in our technical sense-into statements involving relations between natural properties. Solutions have been proposed, but we're not aware of a property-based theory that is thought to offer a satisfying solution to all of these difficulties. The problem, in short, is that the metaphysical restrictions of property-based theories have turned out to be too restrictive. To their credit, they prevent us from attaching the it is a law that' operator to arbitrary sentences. But they seem to prevent us from attaching it to sentences describing regularities as well.

Thus, while we're happy to grant that $P(O \mid N)>>P(O \mid L)$, that doesn't entail that $P(R \mid N)>>P(R \mid L)$. More work is needed to show that non-Humean propertybased theories can explain regularities.

\footnotetext{
${ }^{23}$ See Bird (2007, 213-214), Bigelow et al. (1992), Schurz (2011), and French (2014) for further discussion.

${ }^{24}$ See Tugby (2017).

${ }^{25}$ See, for example, Armstrong (1983: Chapter 7), Vetter (2009), and Collins (2009a).

26 See Tan (2019).

27 See Chen (forthcoming).
} 


\subsection{The Peril of Too Much Structure}

The problems discussed in 3.2 arise because of constraints on the way in which primitive necessities operate in property-based theories. Property-based accounts do appear to avoid the Peril of Insufficient Structure, because they constrain lawhood to statements of patterns. But the specific ways in which they incorporate naturalness have the additional effect of constraining the kinds of patterns that they can explain, so that they are unable to offer a satisfying explanation of regularities with the more sophisticated structure $R$ that is of interest to us. If we have too many constraints, our theory will not have the flexibility required to explain the regularities featured in our best scientific theories. Call this the Peril of Too Much Structure. By way of contrast, notice that Primitivism seems to avoid this peril: for any law that scientists might postulate, primitivists can simply posit a primitive law that produces the relevant regularity. ${ }^{28}$ Primitivism is maximally flexible. However, as we saw in Section 2, that leads to the Peril of Insufficient Structure.

We'll close this section by considering an objection. Given everything we've said, proponents of property-based theories might be tempted to reply as follows:

You haven't shown that there is no possible property-based theory that can succeed in explaining the sophisticated lawlike regularities distinctive of modern science. Consider some theory $N^{*}$ that is still property-based-and so avoids the Peril of Insufficient Structurewhile being flexible enough to accommodate functional laws, conservation laws, and the like. Wouldn't that theory constitute a competitor to Divine Voluntarism?

Reply: As it stands now, we don't know what the content of this hypothetical $N^{*}$ would be, and so we think the burden of proof is on the friend of property-based theories to flesh out and motivate the theory. Nevertheless, we can at least gesture at some difficulties. $N^{*}$ might founder on the Peril of Insufficient Structure, analogously to

\footnotetext{
28 We deny that Primitivists can explain (in the relevant sense) such regularities, but they can at least make sense of the modal force of such laws, their ability to support counterfactuals, etc.
} 
Primitive Laws. Suppose, for example, that we allowed nomic relations of arbitrary complexity, or that we allowed nomic relations to relate non-natural properties. These solutions relax the very constraints that allow property-based theories to avoid the Peril of Insufficient Structure in the first place. A further potential difficulty is this: A mere relaxing of constraints on property-based theories doesn't make it particularly likely that we'd observe regularities as opposed to mere patterns. Moreover, a propertybased theory $N^{*}$ that can accommodate regularities might be considerably more specific than property-based theories in general, and thus $P\left(N^{*}\right)$ might be considerably less than $P(N)$. So even if some property-based theory is capable of explaining regularities in modern science, it may be that Divine Voluntarism offers a better explanation-either because $P(R \mid G)>P\left(R \mid N^{*}\right)$ or because $P(G)>P\left(N^{*}\right)$. With that said, we'll take a closer look at the values of $P(R \mid G)$ and $P(G)$ in Sections 4 and 5, respectively.

\section{Divine Voluntarism and the two perils}

To recap, Primitivism avoids the Peril of Too Much Structure, but it founders on the Peril of Insufficient Structure. Property-based accounts avoid the Peril of Insufficient Structure, but they founder on the Peril of Too Much Structure. As a result, the likelihoods $P(R \mid L)$ and $P(R \mid N)$ are too low to provide a good explanation of regularities. Accordingly, the crucial question is whether there is any middle ground: any space for a theory with enough internal metaphysical structure to avoid the Peril of Insufficient Structure, but enough flexibility to avoid the Peril of Too Much Structure. We think that Divine Voluntarism strikes exactly the right balance, offering an elegant solution to both perils. It has more structure than Primitivism, since it countenances God's power and God's will. But it appears to have less structure-and more flexibility — than property-based theories, since it seems that any regularity that scientists could posit could be a regularity that God could will. The crucial question, then, is this: Should we expect God to have a preference for regularities? In this section, we'll argue that the answer is 'Yes.' We'll start with a modest goal. In 4.1, we'll argue that God probably has preferences concerning order, with the result that $P(O \mid G)$ 
$>>P(O \mid H)$. In 4.2, we'll extend our arguments from order to regularity to show that $P(R \mid G)>>P(R \mid H)$.

\subsection{Divine Voluntarism and order}

Recall that Humeanism can't explain order (or regularities, for that matter), because (i) the set of possible worlds it entails has vastly more disorderly (or irregular) worlds than orderly (or regular) worlds and (ii) the ontology seems to require a uniform probability distribution across Humean possible worlds. The problem for Primitivism is similar. It entails a set of possible worlds isomorphic to that of Humeanism. And like Humeanism, its ontology seems to require a uniform probability distribution over possible laws (and thus over possible worlds), with the result that it confers no explanatory advantages over Humeanism. We'll grant that the set of possible worlds countenanced by Divine Voluntarism is isomorphic to that of both Humeanism and Primitivism. However, there is good reason to think that the ontology of Divine Voluntarism does not require a uniform probability distribution over possible worlds compatible with Divine Voluntarism. In fact, there is good reason to think that the orderly worlds (and as we'll argue in 4.2, regular worlds) countenanced by Divine Voluntarism should receive a disproportionately large portion of the probability distribution. Our overall strategy is to argue that this follows from the concept of God's intentional will.

Our argument has two basic premises.

P1: God might have certain higher-order preferences - that is, preferences directed towards higher-order emergent properties, including moral and aesthetic properties but perhaps others besides, or preferences concerning patterns or the content of laws themselves.

P2: The vast majority of possible higher-order preferences require orderly worlds. 
These premises entail that the probability function that captures God's preferences privileges orderly worlds in such a way that $P(O \mid G)>>P(O \mid H)$.

Let's begin with P1. Why should we think that it's possible for God to have preferences for higher-order emergent properties, especially patterns, order, and moral or aesthetic properties? It seems to follow from the concept of mind itself. This is suggested by what we observe about minds, both introspectively and elsewhere in nature. As for introspection, we find that we have the ability to recognize patterns. Indeed, pattern recognition seems to be constitutive of an important kind of thought. Since we have the ability to recognize patterns, probably, so does God. And if God has that ability, then patterns are, insofar as we can tell, a potential target for God's preferences. As for experience concerning other minds, the more intelligent a being is, the more it values order per se and various goods that require order. Non-sentient beings don't value order at all. Sentient beings have some preference for order, and some preference for moral and aesthetic goods. Birds (e.g. bowerbirds) sometimes value aesthetic goods. Chimpanzees seem to sometimes value moral goods, even if they don't conceptualize them as moral. ${ }^{29}$ And humans care a lot about moral and aesthetic values - even if, sometimes, their goals are evil or in poor taste (more on this in a moment). Our point, in short, is simply that intelligent beings can and do have preferences directed towards higher-order emergent properties (and towards value properties in particular). ${ }^{30}$ Since God is intelligent, God's preferences might be directed toward such targets, instead of being directed toward first-order property distributions only. Again, even if there's no special reason to think that God would in fact share our values, higher-order emergent properties seem to be perfectly legitimate intentional targets, so to speak. Even if we know nothing about God other than that God is a powerful, intelligent being, we should at least be willing to grant that God's preferences might be directed towards moral, aesthetic, and other higher-order emergent properties rather than towards mere first-order property distributions independently of any higher-order properties they instantiate. Notice that we aren't claiming that God does

\footnotetext{
${ }^{29}$ De Waal (2006).

30 They need not be value properties. Suppose that chemical properties are higher-order emergent properties grounded in more fundamental physical properties. A chemist might care about chemical properties, even if they're of no intrinsic aesthetic or moral value. They might simply find them interesting.
} 
in fact care about higher-order properties, nor even that God probably cares about higher-order properties. ${ }^{31}$ Justifying a uniform probability function over possible worlds requires the claim that God would not care about such higher-order properties at all. That's a tall order. P1, after all, makes a very modest claim. We have good reason to accept it.

We'll offer three arguments in support of $\mathbf{P} 2$. The first invokes paradigm moral properties, all of which require a certain degree of order or regularity. The second is based on paradigm aesthetic properties, most of which require a certain degree of order or regularity. The third is based on a more technical notion of compressibility.

First, we should accept $\mathbf{P} 2$ because moral properties require some degree of order. The most-familiar and least-controversial moral properties emerge from conscious states of thinking things. ${ }^{32}$ The physical basis of moral properties requires an extremely high degree of order-namely, the sort of order required for the realization of complex functional properties exemplified in our world by brain states. Moreover, moral goods generally supervene on sentience over time, intentions over time, and preferences over time, and some alleged moral goods (such as fairness, desert, and equality) supervene on large-scale synchronic properties. (Indeed, it's hard even to conceive of how conscious states could realize moral properties in highly disorderly worlds. Could there be morality in worlds in which disembodied minds are simply observing chaotic particular matters of fact, with no ability to make interesting predictions about them and no ability to interact with other minds in predictable ways?) It is important to observe that the same is true of bad-making moral properties; as noted above, we are not committed to the claim that God is morally good. Notice,

31 Though one could. For example, one could argue that God, as an intelligent being, must care about them given moral or aesthetic rationalism, the view that essentially action-guiding normative properties can be known by pure reason (cf. Beiser 2009). If we had some degree of confidence that rationalism of this sort were true, that would be enough for our purposes. Though we do not claim that the God of Divine Voluntarism is theistic, readers might wish to consult some of the literature discussing reasons why a theistic God might prefer a regular universe. See, for example, Swinburne (2004, 99-106). Arguments that some divine attributes imply others are relevant as well (Swinburne 2004, 98ff; Foster 2004, Chapter 8).

32 A few philosophers have argued that there may be ethical value even when there are no conscious beings (cf. Moore 1903: ch. III, $\ 50$ ), but this is a controversial position. In contrast, nearly every ethicist agrees that if there are moral obligations at all, they generally apply to our treatment of conscious organisms. Beyond this, Moore's cited example of goodness-withoutconsciousness still requires regularity. 
further, that our view does not require a commitment to moral realism, because firstorder normative theories still assume that what's morally important, if anything is, are these properties.

Second, we should accept $\mathbf{P} 2$ because most higher-order aesthetic properties require some degree of order. Aesthetic properties often supervene on coherence and unity, both synchronically and over time, and on mere persistence. (Consider the physics and biology behind a piece of music, or the chemistry and biology behind flavor combinations, etc.) Some aesthetic properties, as with moral properties, may require consciousness. If that is so, everything said about moral properties applies to this subset of aesthetic properties. But some aesthetic properties might be wholly independent of consciousness. We do not claim that it is impossible for disorderly things to have aesthetic qualities. A Jackson Pollock painting exhibits a large degree of disorder, at least on the surface. ${ }^{33}$ But part of its aesthetic appeal may be due to its contrast with the high degree of apparent order all around us (or to other artworks, such as those by Piet Mondrian). For comparison, consider something truly disorderly — say, the sort of image you'd expect if a computer were to generate a 1000x1000 image by randomly selecting a color pixel by pixel. There are extraordinarily many such images that do not differ aesthetically in any interesting way: they just look like pure noise. Aesthetically speaking, all of them are lumped together. Insofar as one has a higher-order preference for the aesthetic quality noisy mess, presumably one would be indifferent among them. In contrast, there seems to be a wide range of aesthetically different properties among the various orderly arrangements. This is to say, a being whose aesthetic preferences are directed towards higher-order properties is more likely to prefer order, simply because there are more aesthetically-interesting differences among orderly possibilities. ${ }^{34}$

Our third argument for $\mathbf{P} \mathbf{2}$ is based on the notion of compressibility used in Information Theory. ${ }^{35} \mathrm{~A}$ sequence is compressible, roughly speaking, when it can be summarized $100 \%$ accurately (i.e. losslessly) in fewer bits of information than were

\footnotetext{
33 Pollock's paintings may be more orderly than they might initially appear (Taylor et al 1999). ${ }^{34}$ Our argument concerning aesthetic properties that do not rely on consciousness may depend on our third argument for $\mathbf{P} 2$.

35 See, for example, Shannon (1948), Chaitin (1987), and Adriaans (2019).
} 
originally required to state the sequence itself. For example, consider the following two sequences:
A: 010101010101010101010101010101010101010101010101
B: 001100011010101111010010010010111001100010000101

A can be compressed without loss in multiple ways: '01' 24 times; '0101' 12 times; etc. B is incompressible. If you try to describe it by way of a general pattern, you need more information than is required to write the sequence itself. Each sequence has 48 digits. Now consider the space of possible sequences of $1 \mathrm{~s}$ and 0 s that are 48 digits long. The vast majority of such sequences are incompressible (see, for example, Chaitin (1966; 1969), and Chaitin (2007) for an accessible overview). But as an examination of sequence $\mathbf{A}$ illustrates, sometimes highly orderly sequences are not only compressible but are indeed compressible in many ways, where we can measure the relative degrees of compressibility (some compressions are shorter than others).

How is this relevant to our claim that God is more likely than chance to prefer orderly worlds? The basic idea is straightforward. Given P1, God's preferences might be directed towards compressions of worlds rather than exhaustive point-by-point micro-level descriptions of worlds themselves. Consider two procedures: (1) Pick a possible world at random and actualize it. (2) Pick a possible preference at random and actualize a world satisfying that preference, chosen at random from the worlds compatible with that preference. Procedure (2) is more likely than Procedure (1) to actualize an orderly world, simply because there are more ways to accurately and completely describe orderly worlds than to describe disorderly worlds. (Massively disorderly worlds don't have compressions, but orderly worlds do.) And clearly if we know nothing else about God, but are deciding how likely he is to prefer to create an orderly world, we should assign confidence indifferently across preferences, not across worlds. Thus, if God's preferences can be directed towards compressions-which, for all we know, they might be-then even if we know nothing else about God, we should still expect it to be somewhat likely that God would choose to create an orderly world. ${ }^{36}$

\footnotetext{
${ }^{36}$ Further, it seems reasonable that an intelligent being might care about properties of compressions. In particular, it does not seem odd to suggest that God might be interested in extremely simple, elegant compressions of massive worlds. We'll say more about this in 4.2.
} 
This concludes our argument for why God would be likely to have a preference for orderly worlds. We'll now consider three objections.

First, someone might object that what appears orderly to us is only an artifact of our language. For example, perhaps 'eternal chain of falling dominoes' is languagerelatively orderly. Let the predicate ' $H$ ' mean (in some non-English language) that a phenomenon lasts for 1,000 years, and ' $\mathrm{J}$ ' mean that a phenomenon exists after 1,000 years of time have passed and continues eternally (cf. Lewis 1983: 367 and Goodman 1955). If God “speaks” a language just like English except it has no predicate 'eternal' but does contain ' $\mathrm{H}$ ' and 'J,' then ' $\mathrm{H}$ chain of falling dominoes' (n.b.: these are intentionally quotation marks, not Quine corners) might appear orderly to him, while 'chain of dominoes that's $\mathrm{H}$ for 1,000 years and then becomes J' might appear disorderly. One obvious answer to give is that 'eternal' is a natural predicate in Lewis's (1983) sense, and ' $\mathrm{H}$ ' and 'J' are non-natural, indeed, gruesome. An obvious follow-up question is epistemological: how do we identify naturalness and non-naturalness? We think it's evident that the predicates used in scientific descriptions of regularities are more natural than their gruesome analogues. But there's little else we can say in the space we have here other than to gesture at (for empiricists) the track-record success of science and (for rationalists) the possibility of synthetic a priori perception of naturalness (cf. Hildebrand 2019: 171; BonJour 1998). The latter is especially appealing to us because presumably naturalness is a necessary property (Hildebrand 2019: 165; Lewis 1986: 60-61, n. 44) and so a relatively plausible target of a priori justification. And besides, if you honestly don't think that we have any justification for our choice of language, you probably have doubts about all explanatory arguments.

Second, an anonymous referee suggested a distinction that might bear on our arguments. There are worlds in which God is the creator, and there are worlds in which a God exists without being the creator. Both constitute versions of Divine Voluntarism. However, a non-creator God might not care about the physical world at all. For the sake of argument, let's grant that non-creator gods have less reason to care about the order of nature. It doesn't follow that they have no reason to care about order. All the intelligent beings we know of care about order, despite not all being creators. Moreover, the hypothesis that God exists as creator and has the power to control whether there are patterns (including regularities) seems coherent and doesn't 
strike us as being that much stronger and more radical than Divine Voluntarism in general. We see no reason to think that we should partition these two versions of Divine Voluntarism as follows: The non-creator God worlds get the lion's share of the probability, and the creator God worlds get almost none. But you'd need to defend that claim and the claim that non-Creator gods wouldn't care in order to really damage the Nomological Argument. That feels like a tall order.

Third, in an important paper, Neil A. Manson (2020) explains how a skeptic about natural theology might challenge our ability to discern what God is likely to create. Manson's paper is aimed at the Fine-Tuning Argument, but we can adapt his points to challenge our claim about the value of $P(O \mid G)$ as well. Roughly speaking, Manson argues that the fine-tuning skeptic may be justified in holding that the probability that God would create a certain sort of universe is inscrutable. ${ }^{37}$ There are essentially four ways to make this case. First, the skeptic might argue that no one is justified in making probability judgments at all. We set this aside because it's far beyond the scope of this paper; we simply assume that we have a reasonably good ability to make objective-epistemic-probability judgments. (We do suspect that the denial of this claim might be self-defeating.) ${ }^{38}$ Second, the skeptic might argue that there are so many possible universes God could create that we just can't be reasonably confident that any subset of universes is remotely probable. This may be a powerful objection to the FineTuning Argument, but we've already answered that sort of point as applied to the Nomological Argument: basically, the possibility of having preferences about regularity or higher-order properties at all means God is more likely than chance to prefer an orderly universe. Third, the skeptic might be requesting a systematic procedure for calculating the probability that God would prefer an orderly universe. In our view, this request would be reasonable if we were claiming to assign specific numerical values to the relevant statements of probability. However, since we can get by with rough inequalities, this request seems too demanding. (Must a prosecutor use a systematic

\footnotetext{
${ }^{37}$ Manson actually offers two arguments: simplifying somewhat, the first is that $P(F T \mid G)$ is really low; the second is that $P(F T \mid G)$ is inscrutable. We take our arguments above in 4.1 to address the analogue of the first of Manson's arguments. The crucial issue is whether we have good reason for endorsing a non-uniform probability distribution over the space of worlds. Since we've already addressed this point, we won't rehearse Manson's first argument. ${ }^{38}$ Cf. Cuneo 2007 and Huemer 2017.
} 
procedure and attach numerical estimates to calculating the intrinsic probability that a defendant was present at the murder scene?) Fourth and last, the skeptic might be arguing that for all we know, God has unknown reasons for preferring irregularity and/or disorder. This should remind us of skeptical theism about the Problem of Evil, and it inherits that position's strengths and weaknesses. As for strengths, naturalist skeptics about our argument aren't likely to want to say that skeptical theism is cogent. And as for weaknesses, we can borrow Michael Tooley's reply: for all we know, God might have further, unknown reasons for preferring order (or even regularities) that would cancel out God's possible unknown reasons for preferring disorder (or perhaps mere order). ${ }^{39}$ This answers a related objection as well: that finite beings such as us might not be able to discern various higher-order values that disorderly worlds instantiate or allow. Yes, that's true; but we also might not be able to discern various higher-order values that orderly (and regular) worlds instantiate or allow.

\subsection{Divine Voluntarism and regularity}

We believe that our arguments in 4.1 can be adapted with minor modifications-or in some cases with no modifications - to show that God is more likely than chance to have a preference for regularities in addition to order.

Recall that we supported $\mathbf{P} 1$ by arguing that a preference for order is intimately related to what we know about minds. Well, a preference for regularity seems to fit with what we know about other minds as well, at least insofar as more capable minds tend to have an interest in more sophisticated patterns (when they can find them).

Now recall that we gave three arguments for P2. Do they give us reason to think that God might prefer regularity in addition to order?

Our first argument involved preferences for moral properties. In 4.1, we argued that most moral properties require order-for example, the kind of patterns of brain states that realize mental states. After all, most moral properties are properties of, or depend on properties of, conscious beings. Now replace 'patterns' with 'regularities'. This replacement works simply because mere patterns are not sophisticated enough to ground mental and moral properties. Mental properties won't

\footnotetext{
39 Tooley 2012. See also Tooley 2020: $₫ 3.5 .1$ for an intuitive explanation of the idea.
} 
emerge from the toy pattern "all Fs are Gs"; you need functional realization at a minimum, which involves precisely the sort of sophistication involved in regularities.

Our second argument involved preferences for aesthetic properties. As we noted in 4.1., some aesthetic properties require consciousness. If that's right, then our argument in 4.1 shows that these aesthetic properties require regularities as well, for reasons discussed in the paragraph above. Though it's plausible that some aesthetic properties don't depend on consciousness-consider the simple patterns of Piet Mondrian-most aesthetic properties seem to require regularities. Consider how physicists often treat simplicity, elegance, and beauty as properties of equations; these seem to be perfectly legitimate intentional targets for a divine being, and they seem to require the level of sophistication featured in the equations of modern science. Philosophers' toy examples_-such as that "all Fs are Gs"—-are too simplistic to exhibit such properties in any great measure. But as we suggested above (for example, in footnote 36), these seem to be perfectly reasonable targets for God's preferences.

The third argument for $\mathbf{P} 2$ was based on the notion of compressibility. We argued that there are more possible compressions of orderly worlds than of disorderly worlds. The same is true of regular worlds. Regular worlds are compressible, so insofar as God might have preferences directed towards compressions, God is more likely than chance to have preferences for regular worlds. Moreover, since regular worlds are bighly compressible, and the compressions themselves are good candidates for various aesthetic properties (such as elegance and beauty), this third argument nicely complements the second argument. As a result, Divine Voluntarism is not in the same boat as property-based theories when it comes to the Peril of Too Much Structure. Not only can it accommodate laws having the relevant sort of sophisticated structure, there's reason to think that an intelligent being is likely to look favorably upon such laws. At least, God is more likely than chance to have preferences for them.

At this point, we'll consider an objection suggested to us by a referee. The objection targets our first argument for P2, and portions of our second argument insofar as certain aesthetically valuable states involve mental states of created beings. However, it does not target the compressibility argument, nor our aesthetic arguments that involve valuable states of nature, elegance of the contents of scientific laws, and so on, since these arguments do not involve the assignment of value to states of created 
minds. In any case, one might suspect that God could create embodied moral agents in merely orderly worlds. After all, at least some Divine Voluntarists will hold that God is the author of psycho-physical laws-i.e., that the connection between the physical and mental is nomologically necessary as opposed to metaphysically necessary. If that were so, God would have many options for creating minds, and along with them valuable moral and aesthetic states of affairs. For example, in an objection to the FineTuning Argument, Neil Sinhababu suggests that God could have created very "mindfriendly" laws:

Under more mind-friendly psychophysical laws, protons and electrons themselves could have minds like ours. These laws could dictate that these particles have sensory experiences of all the forces other particles exert on them, with the forces most strongly affecting them giving rise to the psychology of belief and then intentional action. Protons and electrons could yearn to be together, feeling delight at the presence of the other as their opposite charges drew them closer. (Sinhababu 2016, 424)

If mind-friendly laws are on the table, perhaps regularities are unnecessary for the realization of valuable moral and/or aesthetic goods.

For the sake of argument, we'll grant that God has power over the content of psycho-physical laws, that Sinhababu's case is possible, and even that Sinhababu's objection succeeds against the Fine-Tuning Argument. However, by hypothesis, Sinhababu's "electrons in love" acquire the mental states they do because of deep regularities in a sophisticated physical environment. God would need to create regularities in order to create "electrons in love." Thus, Sinhababu's example of mindfriendly laws doesn't pose any problems for the Nomological Argument. However, we do need to engage the following question: Could the possibility of mind-friendly laws in merely orderly worlds pose problems for the Nomological Argument?

Suppose that Sinhababu had asked us to consider a chessboard world consisting solely of a mosaic of alternating black and white squares. The suggestion that the squares love each other in rich, complex, and varied ways seems ludicrousor at any rate much more ludicrous than the possibility of "electrons in love." The only way we can make sense of it would be for God to issue a decree of the following sort: "Let it be a law that Square A1 acquires the exact mental states of Barack Obama 
in the actual world; let it be a law that Square A2 acquires the exact mental states of Michelle Obama in the actual world." It follows that A1 and A2 are in love. There is something very strange about this case: the chessboard seems utterly irrelevant to the valuable states of affairs instantiated in this world. ${ }^{40}$ Moreover, if the relevant mental states are indeed qualitatively identical to those of Michelle and Barack, there is a sense in which regularities have just been smuggled through the back door.

What, then, could it look like for minds to exist in a merely orderly world? Functional realization involved in the mental emerging from the physical is off the table, so presumably such worlds will have to be dualistic. Thus, it is helpful to imagine yourself playing a video game. You are a disembodied soul connected (but somehow not by sophisticated psycho-physical laws) to a "body" in the in-game environment. The game will have to be very simple, of course. By hypothesis, it cannot include a physics engine with any sophistication. We're limited to games like Pong and Super Mario Brothers. (Any game running a plausible 3D graphics engine will have a fairly sophisticated physics at minimum.) Moral properties are exhibited to a lesser extent in simple environments. Consider your options for helping or harming others in these in-game environments: you can bounce a ball. Perhaps, at best, you can "save the Princess," so there might be rudimentary moral properties; we're not claiming that no such properties can exist at all in simple environments, but that the properties that are present are much less interesting and varied. One's enemies, if they exist at all, "die" by essentially disappearing, and it's unclear how anything like real pain could ever exist. One's options are much narrower than your options for helping or harming others in the actual world and in other worlds with scientific regularities. And similarly for aesthetic properties; the Pong environment is much less beautiful than sophisticated worlds in environments with modern physics engines. We think that the scientists who

\footnotetext{
40 The very idea that chessboard-squares could love each other presupposes a substantive and controversial thesis in the philosophy of mind, something like a strong pan-possible-psychism, i.e. that any physical object could be conscious, and indeed conscious enough to realize morally and aesthetically interesting properties. We suspect that most philosophers, and especially most atheists, will reject this view; they will say for example that there are metaphysically necessary limits to the possible psycho-physical laws. It's not obvious to us that the consciousness of a chessboard-square is even conceivable, and even if it were, there are wellknown reasons to doubt that such conceivability implies its possibility. (In the context of philosophy of religion, see e.g. van Inwagen's (1977) "Ontological Arguments" and (1998) "Modal Epistemology.")
} 
regard various regularities to be "elegant" or "beautiful" would agree and would find them more beautiful than mere patterns. Here, then, is the takeaway. The mere existence of minds doesn't suffice to allow all the various valuable states of affairs that might lead God to want to create minds in the first place. Rather, we need minds in worlds with regularities.

To sum up, then, our arguments in 4.1 can be adapted with minor modifications to show that God is more likely than chance to have a preference for regularity. Indeed, we think they suggest that God probably does have a preference for regularity, and thus that $P(R \mid G)>>P(R \mid H)$. Thus, Divine Voluntarism appears to provide the middle ground we're looking for.

\subsection{Summing up}

We've argued that, unlike competing versions of non-Humeanism, Divine Voluntarism avoids both perils. The likelihood $P(R \mid G)$ is much higher than the likelihoods of any other theories we've considered thus far. We thereby have reason to take Divine Voluntarism seriously. However, in spite of these advantages, we suspect that some will object to Divine Voluntarism for a different reason. That is the topic of Section 5.

\section{The prior probability of Divine Voluntarism}

One could accept everything we've said thus far, but argue on independent grounds that Divine Voluntarism faces a different peril of its own: it's simply too implausible. To clarify, according to this objection, the prior $P(G)$ isn't low because one must artificially narrow the theory in order to secure a high likelihood $P(R \mid G)$; rather, $P(G)$ is too low for independent reasons.

In this section, we argue that the prior probability of Divine Voluntarism is sufficiently high to block this objection. Our strategy is to argue that the assignment of priors should be deeply informed by the structure of the theories. We argue that Divine Voluntarism has a reasonably high intrinsic probability (don't worry; we'll explain what we mean by 'intrinsic probability' in just a moment). We hold that its intrinsic probability is high enough, in turn, to confer a sufficiently high prior 
probability for the hypothesis of Divine Voluntarism-i.e. prior to considering other relevant arguments about the existence of supernatural beings — that it beats its leading competitors.

Disclaimer: In employing this strategy, we're interpreting the probabilities as objective epistemic probabilities. If you prefer to interpret probabilities as subjective epistemic probabilities, we hope that you'll still find our argument that Divine Voluntarism deserves a non-negligible prior to be interesting (and perhaps even personally compelling).

\subsection{Prior probabilities and intrinsic probabilities}

In this section, we'll assume that there are objective, epistemic, intrinsic probabilities: that there is some objective fact about one's degree of justification in believing proposition $p$ before examining any evidence $e$ other than the calculation of the intrinsic probability itself (if that counts as "evidence"). This sort of probability is not the same as a prior probability per se, although perhaps one is sometimes justified in using intrinsic probabilities as prior probabilities. A prior probability is one's justification before encountering some specific item of evidence (a prior probability is always prior to something), but usually after other items of evidence. In contrast, intrinsic epistemic probability is a degree of justification in believing that $p$ merely by understanding the content of $p$ and its contraries, and even before employing empirical observation and any other putative evidentiary faculty, except insofar as those faculties allow us to calculate the intrinsic probability itself. While this assumption may be controversial, we suspect that it is less controversial than Divine Voluntarism. ${ }^{41}$ For those who question how pervasive such an assumption is, consider the following example.

Suppose that Monty offers you the choice between three doors, one of which conceals a car (which you want) and two of which conceal goats (which, while

41 According to the PhilPapers surveys, only 15\% of philosophers are theists. But Terence Cuneo (2007) reports (p. 116) that it is very difficult to find a philosopher who endorses epistemic nihilism. In general, philosophers who assert that various theories are justified, or that various arguments are cogent, are committing to some form of epistemic realism, and thus to intrinsic probabilities (cf. Huemer 2017: \5 and passim; Huemer 2016 \5.3). 
charming, aren't your goal). You know that no matter which door you choose, Monty will open a door you didn't choose, revealing a goat. The standard view is that if you initially select Door A, and Monty then (without yet opening Door A) opens Door B to reveal a goat, and offers you the option to switch to Door $C$, then you should take it. ${ }^{42}$ But this judgment is puzzling if there are no such things as intrinsic, epistemic probabilities. In the story, you have the choice between three doors, and there are no apparent differences between them other than their numbering and spatial location, and in fact there is no empirical nor intuitive evidence about what they conceal. Therefore, even if you do have some prior epistemic probability that the car would be behind some particular door, it can't be because of any specific item of evidence. If the likelihood that the car is behind Door $\mathrm{C}$ is to be objectively greater than it was before Monty's opening of Door B, there must be some fact of the matter about the probability-distribution before any door was opened, and certain distributions must be objectively incorrect. (If for some reason you started out justified with certainty in assuming that the car was behind Door A, then it would be incorrect to switch.) In turn, the standard view of the Monty Hall Problem holds that one is initially justified in assigning $1 / 3$ probability to the car's being behind any particular door. Why? The obvious answer is that there are exactly three options and there seems to be exactly as much evidence for each. ${ }^{43}$

Someone might question here whether these assignments report intrinsic probabilities, rather than a cognizer's prior confidences. But without invoking intrinsic probabilities, it is difficult to justify the choice to assign a prior probability of $1 / 3$ to each door. Why should the mere fact that there are three doors mean anything about how rational it is to assign any level of confidence to the car's being behind any particular

42 See e.g. Russell (2010: 464) for a discussion of this problem.

${ }^{43}$ This is the standard view, but of course there are dissenters, e.g. Bradley and Fitelson (2003), who argue that standard intrinsic-probability assumptions are unnecessary to deliver the conclusion that one ought to switch. Our quick reply is to recur to the other judgment we make: intuitively, it is objectively incorrect to begin unity-confident that the car is behind Door $\mathrm{A}$, and objectively incorrect to begin 0.9-confident, and so on, but there is no reason to say it is objectively incorrect to begin $1 / 3$-confident. Indeed, Bradley and Fitelson admit (p. 29) that they need to assume a thesis about prior or intrinsic probability anyway, viz. their assumption (7). We thank an anonymous referee for helping us to see the importance of noting this. 
door? For prior confidences to be objectively correct, they must be based on some objective fact, and we hold that intrinsic probabilities are such an objective fact.

\subsection{Estimating intrinsic probabilities}

The philosophical project of coming up with a fully systematic, uncontroversial way to assign intrinsic probabilities is difficult. ${ }^{44}$ Therefore, we won't attempt it here. Instead, we'll proceed with some intuitive considerations about how to estimate intrinsic epistemic probabilities in particular cases. And in this project, we depart from many other presentations of design arguments. Such presentations commonly don't attempt to estimate an intrinsic probability for theism, but instead simply try to estimate the evidential contribution of some alleged item of evidence, such as apparent biological design or apparent fine-tuning (e.g. Collins 2009b). However, in part because Divine Voluntarism is a weaker (and thus a priori more plausible) explanatory hypothesis than one required for standard design arguments, we think that it's worthwhile to engage in this project.

How, then, should we estimate intrinsic probabilities? Paul Draper (2017: 69 ff.) offers a plausible theory of intrinsic probabilities according to which they depend on the modesty and coherence of a hypothesis. A hypothesis is modest to the degree that it does not commit us to saying very much about the world. A hypothesis is coherent to the degree that its conjuncts or elements cohere well with each other: they fit together well, or they raise, or at least don't lower, each other's (conditional) probabilities. We will estimate the intrinsic probability of Divine Voluntarism by partitioning the probability-space based on modesty and coherence. We assume, of course, that the sum of the probabilities of mutually exclusive and jointly exhaustive individual disjuncts within some proposition cannot exceed the probability of that (disjunctive) proposition itself. With this principle as a guide, we can proceed.

\subsection{The intrinsic probability of Divine Voluntarism}

Our goal is to roughly estimate the intrinsic probability of Divine Voluntarism $P_{i}(G)$. In the next section we'll discuss how our estimate is relevant to the prior probability of

${ }^{44}$ See our discussion on pp. 7-8, especially footnotes 14 and 15. 
Divine Voluntarism $P(G)$. That will be the appropriate time to discuss considerations of ontological parsimony, other evidence for or against the existence of God, and the like. But for now, we'll try to outline a general procedure for estimating $P_{i}(G)$. The idea, in a nutshell, is to provide a taxonomy of theories of natural necessity that carves logical space into broad, coherent, general categories of approximately equal modesty. We'll borrow the general taxonomy from Hildebrand (2020).

To begin, consider two very general hypotheses: Humeanism and nonHumeanism. They are mutually exclusive and jointly exhaustive, so $P_{i}(H \mathrm{v} \sim H)=1$. Pace Hume, they appear equally coherent. Both are exceedingly simple, so there's little room for incoherence in either theory. ${ }^{45}$ They appear equally modest as well. One asserts that there is a big, far-reaching brute fact about distributions of properties while remaining non-committal about the nature of the distribution. The other asserts that there is a big, far-reaching source of natural necessity, while remaining non-committal about the nature of the non-Humean natural necessity. Thus, although they involve different primitives, the two theories in their most general form exhibit a sort of symmetry. As a result, we should grant roughly equal intrinsic probability to both. ${ }^{46}$

Let's turn to the classification of non-Humean theories. Suppose that nature is a mosaic of particular matters of fact. In relation to the mosaic, where are your nomic necessities? They could exist independently of the mosaic and impose structure on it from the outside. Relative to Humeanism, these theories are inflationary, because they posit additional entities. Alternatively, nomic necessities could exist as a part of the mosaic, imposing structure from within. We'll call such theories revisionary, because they revise the Humean description of the facts constituting the mosaic itself. This distinction is exhaustive, but not exclusive, since some accounts posit both sorts of

45 Inspired by Hume, some philosophers believe that primitive modalities are simply unintelligible. We follow Wilson (2010) in thinking that the rejection of primitive modalities is difficult to motivate without a (nowadays unpopular) Humean account of concept formation. Others might think that all non-Humean theories founder on van Fraassen's (1989) inference problem, which challenges non-Humeans to make sense of how their primitives succeed in producing regularities. We follow Schaffer (2016) in thinking that van Fraassen's challenge can be answered via stipulation.

46 In contrast, consider these two mutually exclusive and jointly exhaustive hypotheses: Either there is a god who wishes for nature to include exactly four unicorns or there isn't. Those two hypotheses exhibit an obvious asymmetry in terms of the facts that they can accommodate, so they are not equally modest and do not have an equal intrinsic probability. 
natural necessity. However, both options appear to be perfectly coherent, and both seem equally modest: each holds that these necessities exist; they disagree only about where the necessities come from. ${ }^{47}$

What more can be said about natural necessities? For starters, are they just primitive, full stop, or do they admit of deeper analysis? Both options seem to be perfectly coherent. As for modesty, as before, one hypothesis asserts that a large, important class of phenomena is analyzable and the other asserts that a large, important class of phenomena is primitive. Thus, we'll suppose that primitive and analyzable accounts of non-Humean laws have the same intrinsic probability. (In fact, this supposition might be generous to Primitivism, at least if one is sympathetic to the considerations behind the Principle of Sufficient Reason.) Treating natural necessity as primitive yields Primitivism if you're an inflationist. If you're a revisionist, treating natural necessity as primitive yields something like Primitivism-namely, a theory of the sort proposed by Marc Lange (2009) and Ann Whittle (2009) according to which fundamental modally-robust singular facts are responsible for patterns in nature. ${ }^{48}$

Suppose, then, that natural necessities do admit of deeper analysis. What options are available? Broadly speaking, we can think of three: The analysis might involve properties, intentionality, or something undreamt of. As we've seen, there are property-based variants of both revisionism and inflationism. Revisionism combined with primitive intentionality results in Panpsychism (Dolbeault, 2017). ${ }^{49}$ Inflationism combined with primitive intentionality results in Divine Voluntarism (or something much like it). And as for primitives undreamt of? Well, it would be silly to speculate about what sorts of theories would result given that option, but more on this in a moment. In any case, there is a radical difference between accounts that posit a nonintentional sort of natural necessity (as property-based accounts do) and accounts that involve fundamental intentionality. These two options thus seem equally coherent (for

${ }^{47}$ Of course it's possible for inconsistencies to arise as theories are developed and refined, but this is not unique to non-Humeanism.

${ }^{48}$ We think these theories fall prey to the Peril of Insufficient Structure, because there is no explanation of patterns among the fundamental singular facts, but that claim probably deserves its own paper.

${ }^{49}$ Panpsychism has some structural similarities to the theories of Lange (2009) and Whittle (2009), so we are inclined to think that it is susceptible to the Peril of Insufficient Structure as well. 
the same reason that the above divisions are) and equally modest; presumably only if we were already (question-beggingly) committed to naturalism or theism, etc., would we say that intentional explanations are fundamentally more or less modest.

To wrap up our taxonomy, we'll consider one additional distinction concerning an intelligent being's degree of power/ability. To illustrate, consider this competitor to Divine Voluntarism:

Limited Voluntarism: There is an intelligent being that has the power to intentionally control whether there are regularities (in at least part of the world it inhabits), but it does not have the power to control whether nature is orderly.

If it seems difficult to imagine how a being might be able to control regularities without being a supernatural creator with power over order, consider something like Bostrom's (2003) simulation hypothesis. Our world might be a simulated world-within-a-world, where the enclosing world is understood to be a physical law-governed place. The person running the simulation has power over the regularities in the simulated world, but not over the order (or even regularities) of their own world. This version of Limited Voluntarism is of little relevance to the Nomological Argument. Because it posits regularities in the physical base reality, it simply pushes the explanatory problem back a level. Some versions of Limited Voluntarism do not. For example, perhaps there are many gods, some of them more powerful than others, and one of the less powerful gods creates a simulated reality, despite being unable to control the order of its own reality. This is an interesting hypothesis, but it gives rise to a dilemma, depending on how it is developed. If the "limited" being is very powerful and intelligent, the hypothesis is so similar to Divine Voluntarism that we don't feel the need to consider it carefully in this paper. On the other hand, if the limited being is far less impressive then it's unclear that the hypothesis offers a very good explanation of regularities.

That concludes the taxonomy. Do its divisions group theories in a natural way, generating a classification of theories that are coherent and more-or less equally modest? We think so. For the most part, we've relied on exhaustive distinctions, where the options in question track fundamentally different ontologies. In other words, they 
do not feel arbitrary, but seem to result in a taxonomy of theories that displays at least rough symmetry. We acknowledge one area in which our distinctions are not exhaustive-namely, concerning theories undreamt of. One might be tempted to object that these deserve a much larger intrinsic probability, but that approach threatens to undermine all explanatory arguments.

Finally, let's return to the question "What is the intrinsic probability of Divine Voluntarism?" Forget about precise numbers. The crucial takeaway is this. Insofar as these divisions seem fairly natural - that is, insofar as they involve highly general theories that appear to be of similar modesty - all such theories ought to receive a non-negligible intrinsic probability. Divine Voluntarism seems to be just as coherent and modest as its relevant competitors. Given the generality and modesty of Divine Voluntarism, any reasonable way of carving up our space of possible hypotheses should deliver this same result. This result concerning intrinsic probability will suffice to make our case, since we argued above that there is a massive disparity in likelihoods such as that $P(R \mid G)>>P(R \mid H)$, and in 5.4 we'll argue that the prior probability of Divine Voluntarism $P(G)$ doesn't differ significantly from its intrinsic probability $P_{i}(G)$.

\subsection{From intrinsic probability to prior and posterior probability}

Recap: Here in Section 5, we're considering the prior probability of Divine Voluntarism $P(G)$, and in particular the claim that it is too low for it to be the best explanation of regularities. The first step of our response (5.3) is our argument that the intrinsic probability of Divine Voluntarism $P_{i}(G)$ is non-negligible. In a state of total ignorance, we should set our prior $P(G)$ to the intrinsic probability $P_{i}(G)$. However, we're not operating from a position of total ignorance. The second step of our response (5.4) considers potential evidence against Divine Voluntarism that might lower its prior. Disclaimer: Since we're presenting an ampliative argument, we cannot assume that we've taken into account all relevant evidence. However, we can make a number of points that weigh in favor of setting $P(G)$ close to $P_{i}(G)$. That will suffice for a defense of our claim that Divine Voluntarism beats its relevant competitors. (Remember, we're not arguing that $P(G \mid R)>.5$, but just that $P(G \mid R)>P(T \mid R)$ for leading competitors T.) 
First, someone might argue that the prior probability of Divine Voluntarism is much lower than our estimate, because among analyzable non-Humean theories of laws we should not equally partition the probability space between the regularities' being intentionally created and non-intentionally governed. Instead, given that we are normally inclined to think that most events are mindlessly caused, induction suggests a very low probability for 'intentional creation.' But this argument begs the question. If Divine Voluntarism is true, then there is a sense in which all events have an explanation in terms of God's intentional action. Indeed, Draper (2017: 70 ff.) admits that the minimal theses of Source Physicalism (according to which everything mental is caused by something physical) and Source Idealism (according to which everything physical is caused by something mental) have roughly equal intrinsic probability.

Second, someone might argue that certain evidence against theism renders the prior probability of theism (prior to encountering regularities) to be so low as to be negligible. For example, perhaps Tooley's (2008) version of the Problem of Evil shows that Anselmian theism is vanishingly unlikely. However, Divine Voluntarism does not require a theistic god. A theistic God seems likely to want to create regularities (so that it can create important moral or aesthetic properties), but as we argued in Section 4, we think that a merely intelligent god is still not very unlikely to want to create regularities, even if it has evil intentions. The hypothesis of a "merely intelligent" God is much less susceptible to the Problem of Evil. On a similar subject, someone might argue that in terms of our experience, minds tend to be physical or supervene on physical substrates. Especially if minds tend to depend for their existence on physical regularities, this might lower the prior probability of God. In reply, we can't delve too deeply into the debate between materialism and dualism (or, for that matter, idealism), but we don't think that dualism has been convincingly shown to be vanishingly improbable. More generally, we haven't argued that all minds depend for their existence on physical regularities, but instead, that some immaterial minds would have reasons (detailed in $\int 4$ ) to create minds that do depend on physical regularities. In any case, if this objection were decisive, it would undermine nearly all natural-theology arguments, so we don't believe it needs further attention here.

Third, one might argue that non-Humean theories should be assigned a significantly lower prior probability due to considerations of ontological parsimony. 
Such principles are controversial (Huemer 2009; Sober 2009; Kriegel 2013: 18 ff.; Metcalf 2016), but even if we grant them, it seems implausible that they would have sufficient impact to take us from a non-negligible intrinsic probability to a truly negligible prior.

The last point we want to make in favor of setting $P(G)$ close to $P_{i}(G)$ is that intrinsic probabilities seem to be a good starting point for the type of metaphysical hypotheses we are considering. Immediate experience does not directly inform us which theory is true. And as for background scientific knowledge, the Nomological Argument is concerned with an explanation of the fact that our world is conducive to scientific inquiry in the first place, so our question is at a level of abstraction above whether our explanation itself coheres with any specific scientific theory. In general, this is to say that any a posteriori argument for one metaphysical hypothesis over another (of the sort we are considering here) will have to rely on intrinsic probabilities of the sort we've defended. (We've argued that such probabilities can be understood and defended as objective, but subjectivists will also have to start with a prior confidence in some metaphysical hypothesis, and many philosophers will start with a prior confidence $P(G)$ that is not extremely low.)

Therefore, in assigning a prior probability to Divine Voluntarism, it seems appropriate to begin with its intrinsic probability. Though considerations of ontological parsimony might result in a lower prior, they are too weak to result in a significantly lower prior. We conclude that Divine Voluntarism has a sufficiently high prior probability that it does indeed provide a better explanation of regularities than the competing theories we've considered. As noted, there might be other evidence against Divine Voluntarism that renders the all-things-considered epistemic probability of such an explanation lower than its proponents might like, but there are no obvious candidates for such evidence.

\section{Conclusion}

We have argued that Divine Voluntarism offers a better explanation of natural regularities than its most-prominent competitors do. It has enough internal structure that it predicts regularities (as opposed to irregularities, as Humeanism and Primitivism 
predict). But its structure is sufficiently flexible that it can explain any regularity that has been or could be devised by natural scientists (unlike certain property-based theories of laws). Further, we've argued that it's reasonable to assign Divine Voluntarism a non-negligible intrinsic and therefore prior probability, given that (i) Divine Voluntarism is approximately as modest and general as its main competitors at that level of explanation; (ii) extant objections to non-Humeanism in general and to explanatory arguments in general are unsuccessful (a claim we've simply assumed, rather than defended); and (iii) extant arguments for atheism (such as the Problem of Evil) and against other teleological arguments do not apply to Divine Voluntarism.

It would take a much longer work to fully defend the Nomological Argument against all possible rivals, or to show that justifying Divine Voluntarism would in turn justify classical or Anselmian theism. But we take our arguments to constitute an important step toward a defense, so that Divine Voluntarism at least warrants attention. At the end of the day, you might be left with the feeling that our appeal to a god is like cheating. But that's exactly our point. ${ }^{50}$

\section{References}

Adams, Dani. 2018. "God and Dispositional Essentialism: An Account of the Laws of Nature.” Pacific Philosophical Quarterly 99: 293-316.

Adriaans, Pieter, "Information." The Stanford Encyclopedia of Philosophy (Spring 2019 Edition), Edward N. Zalta (ed.). < https://plato.stanford.edu/archives/spr2019/entries/information/>.

Armstrong, David. 1983. What is a Law of Nature? Cambridge: Cambridge University Press.

Armstrong, David. 1989. Universals: An Opinionated Introduction. Boulder, Colo.: Westview Press.

\footnotetext{
${ }^{50}$ We are grateful to Meghan Page, Chelsea Haramia, two anonymous referees, and audiences at the Society of Christian Philosophers 40 th Anniversary Conference (2018), the New Directions in Theology and the Philosophy of Science Workshop (Concordia University of Edmonton, 2019), and the Alabama Philosophical Society (2019). This paper has improved significantly as a result of their comments, criticisms, and suggestions.
} 
Barrow, John D. and Frank J. Tipler. 1986. The Anthropic Cosmological Principle. New York: Oxford University Press.

Beebee, Helen. 2000. “The Non-Governing Conception of Laws of Nature.” Philosophy and Phenomenological Research 61:571-594.

Beiser, Frederick C. 2009. Diotima's Children: German Aesthetic Rationalism from Leibniz to Lessing. Oxford: Oxford University Press.

Bigelow, John, Ellis, Brian, and Lierse, Caroline. 1992. “The World as One of a Kind: Natural Necessity and Laws of Nature." British Journal for the Philosophy of Science 43:371-388.

Bird, Alexander. 2007. Nature's Metaphysics: Dispositions, Laws and Properties. Oxford: Oxford University Press.

Bostrom, Nick. 2003. “Are We Living in a Computer Simulation?” The Philosophical Quarterly 53 (211): 243-255.

Bradley, Darren and Branden Fitelson. 2003. "Monty Hall, Doomsday and confirmation." Analysis 63(1): 23-31.

Carroll, John. 1994. Laws of Nature. Cambridge: Cambridge University Press.

Chaitin, G. J. 1966. "On the Length of Programs for Computing Finite Binary Sequences." Journal of the Association for Computing Machinery 13 (4): 547-569.

Chaitin, G. J. 1969. "On the Length of Programs for Computing Finite Binary Sequences: Statistical Considerations." Journal of the Association for Computing Machinery 16 (1): 145-159.

Chaitin, G. J. 1987. Algorithmic Information Theory. Cambridge: Cambridge University Press.

Chaitin, G. J. 2007. "Algorithmic Information Theory: Some Recollections." https://arxiv.org/abs/math/0701164

Chen, Eddy Keming. Forthcoming. "The Past Hypothesis and the Nature of Physical Laws.” In Barry Loewer, Eric Winsberg, and Brad Weslake (eds.), Time's Arrows and the Probability Structure of the World, Harvard University Press. Preprint: <https://arxiv.org/abs/2008.00611>

Climenhaga, Nevin. 2017. "Inference to the Best Explanation Made Coherent." Journal of Philosophy 114(5): 251-73. 
Collins, Robin. 2005. "Fine-Tuning Arguments and the Problem of the Comparison Range”. Philosophia Christi 7:385-404.

Collins, Robin. 2009a. "God and the Laws of Nature.” Philo 12:142-171.

Collins, Robin. 2009b. “The Teleological Argument: An Exploration of the FineTuning of the Universe." In William Lane Craig and J. P. Moreland (eds.), The Blackwell Companion to Natural Theology (Malden, MA: Wiley-Blackwell), pp. 20281.

Cuneo, Terence. 2007. The Normative Web: An Argument for Moral Realism. New York, NY: Oxford University Press.

De Waal, Frans. 2006. Primates and Philosophers: How Morality Evolved. Princeton, NJ: Princeton University Press.

Dolbeault, Joël. 2017. “Laws of Nature or Panpsychism?” Journal of Consciousness Studies 24: 87-110.

Draper, Paul. 2017. "God, Evil, and the Nature of Light." In Chad Meister and Paul K. Moser (eds.), The Cambridge Companion to the Problem of Evil (New York, NY: Cambridge University Press), pp. 69-84.

Dretske, Fred. 1977. "Laws of Nature.” Philosophy of Science 44:248-268.

Dumsday, Travis. 2012. “Laws Don’t Have Ceteris Paribus Clauses, They Are Ceteris Paribus Clauses.” Ratio 26(2): 134-147.

Dumsday, Travis. 2013. "Using Natural Kind Essentialism to Defend Dispositionalism.” Erkenntnis 78: 869-880.

Ellis, Brian. 2001. Scientific Essentialism. Cambridge: Cambridge University Press.

Fales, Evan. 1990. Causation and Universals. New York: Routledge.

Filomeno, Aldo. 2019. "Are Non-Accidental Regularities a Cosmic Coincidence? Revisiting a Central Threat to Humean Laws." Synthese. DOI: <https://doi.org/10.1007/s11229-019-02397-1>

Foster, John. 2004. The Divine Lawmaker. Oxford: Oxford University Press.

French, Steven. 2014. The Structure of the World: Metaphysics and Representation. Oxford: Oxford University Press.

Fumerton, Richard. 1995. Metaepistemology and Skepticism. Lanham, MD: Rowman \& Littlefield. 
Goodman, Nelson. 1955. Fact, Fiction, and Forecast. Cambridge, MA: Harvard University Press.

Hájek, Alan. 2019. "Interpretations of Probability." The Stanford Encyclopedia of Philosophy (Fall 2019 Edition). Ed. Edward N. Zalta. URL: $<$ https://plato.stanford.edu/archives/fall2019/entries/probabilityinterpret $>$.

Hildebrand, Tyler. 2013. “Can Primitive Laws Explain?” Philosophers' Imprint 13 (15):115.

Hildebrand, Tyler. 2018. "Natural Properties, Necessary Connections, and the Problem of Induction." Philosophy and Phenomenological Research 96(3): 668-689.

Hildebrand, Tyler, 2019. "Naturalness Constraints on Best Systems Accounts of Laws." Ratio 32(3): 163-72.

Hildebrand, Tyler. 2020. "Non-Humean Theories of Natural Necessity." Philosophy Compass 15(5): 1-14.

Huemer, Michael. 2009. "When is Parsimony a Virtue?” The Philosophical Quarterly 59 (235): 216-36.

Huemer, Michael. 2016. "Serious Theories and Skeptical Theories: Why You Are Probably Not a Brain in a Vat.” Philosophical Studies 173 (4): 1031-52.

Huemer, Michael. 2017. "There Is No Pure Empirical Reasoning." Philosophy and Phenomenological Research 95(3): 592-613.

Kriegel, Uriah. 2013. "The Epistemological Challenge of Revisionary Metaphysics." Philosophers' Imprint 13 (12): 1-30.

Lange, Marc. 2009. Laws and Lawmakers. Oxford: Oxford University Press.

Lewis, David. 1983. "New Work for a Theory of Universals." Australasian Journal of Philosophy 61:343-377.

Loewer, Barry. 1996. "Humean Supervenience.” Philosophical Topics 24:101- 127.

Lowe, E. 1989. Kinds of Being. New York: Basil Blackwell.

Lowe, E.J. 2006. The Four-Category Ontology. New York: Oxford University Press.

Maudlin, Tim. 2007. The Metaphysics Within Physics. Oxford: Oxford University Press.

Manson, Neil A. 2003. "Introduction.” In Neil A. Manson (ed.), God and Design: The Teleological Argument and Modern Science (New York, NY: Routledge), pp. 1-23.

Manson, Neil A. 2009. “The Fine-Tuning Argument”. Philosopby Compass 4:271-286. 
Manson, Neil A. 2020. "How Not to Be Generous to Fine-Tuning Sceptics.” Religious Studies 56:303-17.

Maroney, Owen. 2020. "Information Processing and Thermodynamic Entropy.” The Stanford Encyclopedia of Philosophy (Spring 2020 Edition). Ed. Edward N. Zalta. URL:

<https://plato.stanford.edu/archives/spr2020/entries/information-

$$
\text { entropy/> }
$$

McGrew, Timothy and McGrew, Lydia. 2005. "On the Rational Reconstruction of the Fine-Tuning Argument”. Philosophia Christi 7:425-443.

McGrew, Timothy, McGrew, Lydia, and Vestrup, Eric. 2001. "Probabilities and the Fine-Tuning Argument: A Sceptical View”. Mind 110:1027-1038.

Mellor, D.H. 2005. Probability: A Philosophical Introduction. New York: Routledge.

Metcalf, Thomas. 2016. "Ontological Parsimony, Erosion, and Conservatism." Metaphilosophy 47(4-5): 700-18.

Metcalf, Thomas. 2018. "Fine-Tuning the Multiverse." Faith and Philosophy 35(1): 3-32.

Moore, G. E. 1903. Principia Ethica. Cambridge, UK: Cambridge University Press.

Mumford, Stephen. 2004. Laws in Nature. London: Routledge.

Oderberg, David S. 2007. Real essentialism. New York: Routledge.

Orr, James. 2019. “No God, No Powers.” International Philosophical Quarterly 59(4): 411426.

Plantinga, Alvin. 2016. "Law, Cause, and Occasionalism.” In Michael Bergman and Jeffrey Brower, Reason and Faith: Themes from Richard Swinburne (Oxford: Oxford University Press), pp. 126-44.

Pruss, Alexander R. 2005. "Fine- and Coarse-Tuning, Normalizability, and Probabilistic Reasoning." Philosopbia Christi 7 (2): 405-23.

Russell, Bruce. 2010. "Intuition in Epistemology." In A Companion to Epistemology, Second Edition, ed. Jonathan Dancy, Ernest Sosa, and Matthias Steup (Malden, MA: Blackwell), 464-68.

Schaffer, Jonathan. 2008. "Causation and Laws of Nature.” In Theodore Sider, John Hawthorne, and Dean Zimmerman (eds.), Contemporary Debates in Metaphysics, 82-107. Oxford: Blackwell. 
Schaffer, Jonathan. 2016. "It Is the Business of Laws to Govern.” Dialectica 70: 577588.

Schurz, Gerhard. 2011. "Review of Nature's Metaphysics: Laws and Properties." Erkenntnis 74:137-142.

Segal, Aaron. Forthcoming. "Humeanisms: Metaphysical and Epistemological." Synthese.

Shannon, C. E. 1948. “A Mathematical Theory of Communication.” The Bell System Technical Journal XXVII(3): 379-423.

Sider, Theodore. 2011. Writing the Book of the World. New York: Oxford University Press.

Sinhababu, Neil. 2016. "Divine Fine-Tuning vs. Electrons in Love." American Philosophical Quarterly 53 (4): 423-432.

Sober, Elliott. 2009. "Parsimony Arguments in Science and Philosophy-A Test Case for Naturalismp." Proceedings and Addresses of the American Philosophical Association 83(2): $117-55$.

Swinburne, Richard. 2004. The Existence of God, revised edition. Oxford, UK: Oxford University Press.

Swinburne, Richard. 2006. "Relations Between Universals, Or Divine Laws?" Australasian Journal of Philosophy 84:179-189.

Tan, Peter. 2019. "Ideal Laws, Counterfactual Preservation, and the Analyses of Lawhood." Australasian Journal of Philosophy. DOI: < https://doi.org/10.1080/00048402.2019.1638950>.

Taylor, R., Micolich, A. \& Jonas, D. "Fractal analysis of Pollock's drip paintings." Nature 399, 422 (1999). https://doi.org/10.1038/20833

Tooley, Michael. 1977. “The Nature of Laws." Canadian Journal of Philosophy 7: 667698.

Tooley, Michael. 2008. “Does God Exist?” In Alvin Plantinga and Michael Tooley, Knowledge of God (Malden, MA: Blackwell), pp. 70-150.

Tooley, Michael. 2011. "The Skeptical Challenges of Hume and Berkeley: Can They Be Answered?" Proceedings of the American Philosophical Association 85(2):27-46.

Tooley, Michael. 2012. "Inductive Logic and the Probability that God Exists: Farewell to Skeptical Theism.” In Jake Chandler and Victoria S. Harrison (eds.), 
Probability in the Philosophy of Religion (Oxford, UK: Oxford University Press), pp. 144-64.

Tooley, Michael. 2020. "The Problem of Evil." In E. N. Zalta (ed.), The Stanford Encyclopedia of Philosophy, Spring 2020 Edition.

https://plato.stanford.edu/archives/spr2020/entries/evil/

Tugby, Matthew. 2013. "Platonic Dispositionalism.” Mind 122:451-480.

Tugby, Matthew. 2017. “The Problem of Retention.” Synthese 194: 2053-2075.

Van Fraassen, Bas. 1989. Laws and Symmetry. Oxford: Clarendon Press.

Van Inwagen, Peter. 1977. “Ontological Arguments.” Noûs 11: 375-395.

Van Inwagen, Peter. 1998. "Modal Epistemology.” Philosophical Studies 92: 67-84.

Vetter, Barbara. 2009. “Review of Nature’s Metaphysics: Laws and Properties.” Logical Analysis and History of Philosophy 12:320-328.

Weisberg, Jonathan. 2019. Odds and Ends: Introducing Probability and Decision Theory with a Visual Emphasis (v0.2 Beta). Available online: $<$ https://jonathanweisberg.org/vip/>

White, Roger. 2000. "Fine-Tuning and Multiple Universes.” Noûs 34(2): 260-76.

Whittle, Ann. 'Causal Nominalism.' Dispositions and Causes. Ed. Toby Handfield. Oxford: Clarendon Press, 2009. 242-285.

Wilson, Jessica. 2010. “What is Hume's Dictum, and Why Believe It?” Philosophy and Phenomenological Research, 80(3): 595-637. 